\title{
Terminal Costs for On-Line Searching
}

\begin{abstract}
A methodology is presented by which a librarian rationally can choose a terminal, using rather easily obtained estimates of the important variables: cost-per-minute connect time; estimated time of average search; the ratio of input to output time; and the cost per month for a two-year lease of a terminal. The methodology is exemplified by comparing terminals which operate at speeds varying from 10 to 120 characters per second. With the estimates presented here, per-search cost is at a minimum if the slowest and least expensive terminal is used for 1-25 searches per month. Cost per search is minimized for a 30-character-per-second terminal if used for 10-113 searches per month and for a 120-character-per-second terminal if used for 43-133 searches per month.
\end{abstract}

$\mathbf{P}$ ROFESSIONAL LITERATURE SEARCHING has proved useful in many specialized situations. Doctors, attorneys, researchers, and planners make use of it frequently although not as often as they might because of the costs in time and money. The rapid development of equipment, data bases, and associated cost reduction of on-line bibliographic searching is changing this situation., ${ }^{1,2}$ Hock indicates that accessing external data bases is feasible and costs are reasonable for the university library. However, he finesses the actual equipment cost estimates by saying "equipment can be rented for about $\$ 80$ per month on

John Wish is associate professor, College of Business Administration, University of Oregon, Eugene, and Craig Collins and Vance Jacobson were students in the graduate program of the College of Business Administration. This study was partially supported by a research grant from the College of Business Administration, University of Oregon. The authors acknowledge the helpful assistance of Dr. Margaret Meyn, M.D., and librarian at Sacred Heart General Hospital, Eugene, in the preparation of this article. up, and service contracts are about $\$ 20$ per month."3

Bonn and Heer present one of the few useful articles concerning telecommunications equipment for on-line searching. ${ }^{4}$ Their basic tutorial is recommended to readers who are not familiar with the general kinds of equipment available for on-line searching. However, they do not develop any rationale for choosing one type of terminal over another. Neither do they tell where to obtain comparative information about terminals that might be used for on-line searching.

Choosing the optimal computer terminal for a library system can be difficult. A methodological approach to making an economic decision is presented here. This analysis makes the librarian aware of factors influencing total cost and the point at which one terminal becomes more efficient than another. The lowest total cost per search using on-line computer terminal can be calculated easily.

\section{On Choosing a Terminal}

The choice of a terminal is primarily economic. It is a function of both fixed 
and variable costs. The cost analysis requires this information:

1. Cost-per-minute connect time.

2. Estimated length of average search (time).

3. The ratio of human input time to computer output time.

4. Monthly cost of the computer terminal. (Terminals may be leased. If purchased, the cost can be allocated on a monthly basis over some reasonable time.)

This information affords easy estimates of total monthly cost expected from a specific terminal for a given number of searches performed. The analysis assumes constant off-line printing of citations and constant labor costs. Typically, the faster the terminal prints, the greater the monthly cost thus creating an economic trade-off between low monthly terminal cost and more connect time. A detailed analysis follows.

\section{VARIABLE Costs}

\section{Cost-Per-Minute Connect Time}

Cost-per-minute connect time is strictly limited to cost of data bases and telephone hookup. In early 1977 Lockheed's DIALOG information retrieval service had an average cost per connect hour of about fifty-eight dollars, or just under one dollar per connect minute. (Average cost per connect hour from Lockheed is used merely for the purpose of exemplifying our model. The reader should understand that upon performing this analysis, he or she should compute a cost-per-hour connect time most suitable to the local situation. Subsidization can greatly reduce the cost of connect time as in the case of MEDLINE. Professional users such as physicians and pharmacologists are subsidized by the National Library of Medicine. $)^{5}$

On the other hand, for most users there is some form of long distance line charge. Many users dial the on-line service through TELENET or TYMSHARE which have fees of around ten dollars per hour. For demonstration of the methodology a one dollar cost per connect minute is assumed.

\section{Estimated Time of an Average Search}

The length of a search varies according to several factors:

a. The expertise of the operator.

b. The speed of the terminal and the choice of format for printing citations (assuming all abstracts are printed off-line).

c. The extent to which the search is preplanned including preparations for alternate searching strategies.

Expertise of the terminal operator covers several elements. An experienced operator will have a faster reaction to computer questions and faster implementation of alternative search plans. An experienced literature searcher should not only be a good terminal operator but should know the limitations of the data base and realities of human indexing. Being familiar with the subject matter and having a thesaurus which is applicable to the data base are very helpful and should be used prior to beginning a search. ${ }^{6}$

The speed of the terminal determines how fast a terminal can print out information received from the computer. It logically follows that a slower terminal will increase the average on-line search time. (This will be discussed in detail later.) Computer response time also increases average on-line search time, but measurement and control by users is difficult if not impossible. Therefore, it is assumed that any increase in search time due to computer response delay is external and will be the same for all users regardless of the terminal. Computer response time is ignored in these calculations.

Printing citations on-line will increase the computer connect time. Most searchers who use teletype or portable terminals typically limit the number of 
citations and receive off-line printouts.

Connect time per search varies. The range seems to be between five and forty-five minutes. In a demonstration at the University of Oregon in February 1975, fifty-six inexperienced searchers using a Model 33 Teletype and nine of Lockheed's data bases averaged nine minutes connect time per search ${ }^{7}$ (see Wish and Wish ${ }^{1}$ ).

At Sacred Heart General Hospital in Eugene, Oregon, Dr. Margaret Meyn and two associates conducted 465 searches from January to July 1974 and averaged 9.27 minutes connect time per search. Every searcher was experienced and used a Model 33 Teletype. Dr. Meyn tried to limit author and title citations printed on-line to twenty-five, while all abstracts were printed off-line. On the other hand, Elman reported an average on-line search time of $45 \mathrm{~min}$ utes. ${ }^{8}$ Benenfield and associates report 37 minutes average connect time. ${ }^{9}$ For this demonstration of the methodology, an average connect time of 10 minutes is assumed.

\section{Ratio of Human Input Time to Computer Output Time}

This can be defined as the time spent by the human operator inputting data to the computer in relation to the time spent by the computer searching and printing out a reply. This ratio can vary according to the same factors that apply to the length of search. These are: the number of users searching at the same time, the experience of the terminal operator, the type of search being made, and the speed of the terminal. An experienced operator who knows the communication code with the computer and preplans searches can reduce his or her input : output ratio to $1: 9$. This means that during ten minutes connect time the operator uses one minute and the computer uses nine minutes. An inexperienced terminal operator who doesn't know the computer code language could have a 2:1 input: output ratio. This method is exemplified using both $1: 9$ and $2: 1$ input : output ratios.

\section{Fixed Costs}

\section{Monthly Lease of Three Different Terminals}

Terminal cost is closely related to speed. Speed is important for two reasons: (a) cost-per-minute connect time; and (b) time taken to receive information. Since a great proportion of connect time is spent by the computer printing out information, the speed of a terminal becomes a prime economic trade-off. Speed can be measured in characters typed per second (CPS). Three machines that make hard copy available will be compared in this example: one, a Teletype Model 33 which types at a rate of $10 \mathrm{CPS}$; two, a CDI 1030 which types at a rate of $30 \mathrm{CPS}$; and finally, a Teletype Model 40 which types at $120 \mathrm{CPS}$. (See Table 1.) ${ }^{10}$

Libraries may already have a Teletype they are using for interlibrary loan that can be modified for the purpose of on-line searching. Still, for the demonstration of the methodology, a terminal will be allocated entirely to on-line searching.

The leasing cost of computer terminal per month is considered a fixed cost for the purpose of this analysis. A fixed

TABLE 1

Relationship of OutPut Speed Measured IN CPS

\begin{tabular}{lrc}
\hline \hline \multicolumn{1}{c}{ Terminal Model } & CPS & $\begin{array}{c}\text { Relationship } \\
\text { in Time }\end{array}$ \\
\hline Teletype Model 33 & 10 & 1 \\
CDI 1030 & 30 & $1 / 3$ \\
Teletype Model 40 & 120 & $1 / 12$ \\
\hline
\end{tabular}

- The equipment designed for the very heavy user is ignored. Lockheed and other data wholesalers make available much faster terminals which operate over direct leased telephone lines for $\$ 500$ per month, plus the telephone line charge of more than $\$ 1.00 /$ mile per month from origin to destination. (The exact charges depend upon whether the route is intrastate or interstate and whether it is on a high- or low-density route). 
cost may be defined as a cost that does not vary from month to month according to changes in the number of searches performed, average length of search, and input : output ratio. Therefore, monthly leasing costs are "fixed costs."

Table 2 shows an approximate listing of monthly leasing rates for computer terminals used in this example.

\section{Other Costs}

Noise of computer terminals is a hidden cost. The noise can be an influence on which terminal a person wants to lease and where the terminal is to be located in the library. From a marketing viewpoint, the terminal should be located in an area of high traffic flow. From the client's viewpoint, he or she might prefer a soundproof room of some sort. There are advantages and disadvantages to both. Noise may cause complaints from regular patrons, but an isolated cubicle might not be visible enough to encourage sufficient use of on-line searching. From the operator's standpoint, noise becomes bothersome and tiring, cutting severely into operator efficiency if he or she is on-line for very long.

Other costs which may be considered are labor costs and the fee for printing citations and abstracts off-line. Labor costs would be the monthly payment of someone hired to work the terminal. The opportunity costs of labor can be

TABLE 2

Approximate Monthly Leasing Rates

\begin{tabular}{lc}
\hline \hline \multicolumn{1}{c}{ Terminal Model } & $\begin{array}{c}\text { Approximate } \\
\text { Cost/Month }\end{array}$ \\
\hline Teletype Model 33 & $\$ 70.00$ \\
CDI 1030 & $\$ 125.00$ \\
Teletype Model 40 & $\$ 220.00$ \\
\hline
\end{tabular}

put into the model by assuming the average cost per month and adding it to the "fixed costs per month" total used in the analysis. This becomes extremely hard to estimate if the librarian has merely assumed this additional responsibility. Printing off-line is generally charged per citation and is not at all related to the type of terminal used. It is assumed that the client will pay the total cost of all citations printed offline. Thus for the purposes of this analysis the only fixed cost to be considered is the leasing rate for the computer terminals which is assumed to vary from $\$ 70$ to $\$ 220$ per month.

\section{How Cost per Search Varies}

The variable cost per search may be expressed algebraically, as shown in Figure 1.

Comparison of the three terminals previously mentioned is shown in Table 3 for two separate input: output ratios. This assumes an average search of ten minutes and connect time of one dollar per minute.

$$
\left[{ }^{(\text {input })(\mathbf{A})}+\frac{(\text { output })(\mathbf{A})}{(\text { multiple speed of output })}\right]
$$$$
\times \quad\left[\begin{array}{l}
\text { Cost-per-minute } \\
\text { connect time }
\end{array}\right]=\begin{aligned}
& \text { Average variable } \\
& \text { cost per search }
\end{aligned}
$$

Where: $\mathbf{A}=$

Average length of search using Model 33

$$
\text { Output + Input }
$$

Input $=$ the first number used in the input : output ratio

Output $=$ the second number used in the input : output ratio

Multiple speed of output $=$ the relative speed from one terminal to another. Thus the CDI 1030 terminal is three times as fast as Telety pe Model 33. Three is the multiple speed of output.

Fig. 1. A Formula to Determine Cost per Search 
TABLE 3

Average Variable Cost per Search ${ }^{\circ}$

\begin{tabular}{|c|c|c|c|}
\hline Terminal Model & $\begin{array}{l}\text { Relative } \\
\text { Speed } \dagger\end{array}$ & $\begin{array}{c}\text { Input : output } \\
1: 9\end{array}$ & $\begin{aligned} \text { Input : output } \\
2: 1\end{aligned}$ \\
\hline \multirow{4}{*}{$\begin{array}{l}\text { Teletype } \\
\text { Model } 33 \\
\text { CDI } 1030 \\
\text { Teletype } \\
\text { Model } 40\end{array}$} & & & \\
\hline & $\begin{array}{c}1(\mathrm{X}) \\
1 / 3(\mathrm{X})\end{array}$ & $\begin{array}{l}\$ 10.00 \\
\$ 4.00\end{array}$ & $\begin{array}{l}\$ 10.00 \\
\$ 7.78\end{array}$ \\
\hline & $1 / 1_{2}(X)$ & $\$ 1175$ & 604 \\
\hline & & 411.65 & $\$ 0.94$ \\
\hline
\end{tabular}

- The calculations were arrived at in the following manner:

$$
\begin{aligned}
& 2: 1 \text { input : output ratio } \\
& {\left[2(3.33)+\frac{1(3.33)]}{1} \$ 1.00=\$ 10.00\right.} \\
& {\left[2(3.33)+\frac{1(3.33)]}{3}\right] \$ 1.00=\$ 7.78} \\
& {\left[2(3.33)+\frac{1(3.33)]}{12} \$ 1.00=\$ 6.94\right.} \\
& \text { Where } A=\frac{10}{2+1}=3.33
\end{aligned}
$$

† The denominator of relative speed is equal to the multiple of speed output of the Model 33 terminal.

\section{Total Costs}

The variable cost per search shown in Table 3 is only part of the story, however. The monthly leasing costs shown in Table 2 must be added in so that the total cost per search can be determined. Total costs can be calculated by dividing the estimated number of searches per month into the monthly lease cost and then adding the fixed costs to the variable costs as shown in Table 4.

Thus the library with ten searches per month, a ten-minute search time, and a $2: 1$ input to output ratio would find the Teletype Model 33 providing the lowest total cost (variable cost of $\$ 10$ plus a fixed cost of $\$ 7.00$ for a total cost of $\$ 17.00)$. On the other hand, the library with 100 searches would find the CDI 1030 providing the lowest total cost (variable cost of $\$ 7.78$ plus a fixed cost of $\$ 1.25$ for a total cost of $\$ 9.03$ per search).

A simple method for calculating the minimum cost over a range of possible searches per month is to use the graphic method of break-even analysis which is taught in the beginning courses of managerial economics. Figure 2 is for input $:$ output $=1: 9$. Figure 3 is for

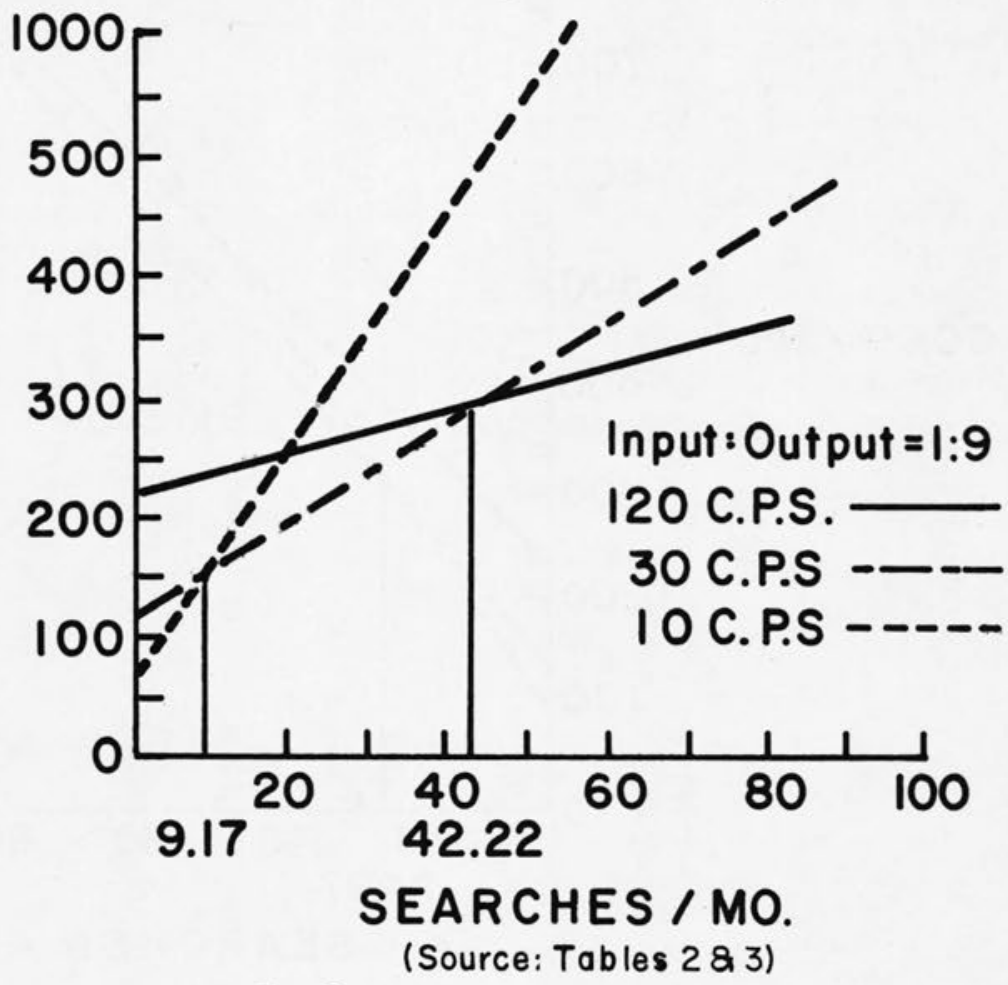

Fig. 2

Calculating the minimum cost (input : output $=1: 9$ ). 
input $:$ output $=2: 1$. Exact points of intersection read to the $\mathrm{X}$ axis are the number of searches per month where total cost ( fixed costs + per search costs)

TABLE 4

Estimated Fixed Costs PER MONTH FOR Three Different Terminals Assuming 10 SEARCHES PER MONTH AND 100 SEARCHES PER MONTH

\begin{tabular}{|c|c|c|c|}
\hline \multirow[b]{2}{*}{ Terminal Model } & \multirow[b]{2}{*}{$\begin{array}{c}\text { Monthly } \\
\text { Lease }\end{array}$} & \multicolumn{2}{|c|}{$\begin{array}{l}\text { Fixed Costs per } \\
\text { Search with: }\end{array}$} \\
\hline & & $\begin{array}{c}10 \\
\text { searches }\end{array}$ & $\begin{array}{l}100 \\
\text { searches }\end{array}$ \\
\hline Teletype Model 33 & $\$ 70.00$ & $\$ 7.00$ & $\$ 0.70$ \\
\hline CDI 1030 & $\$ 125.00$ & $\$ 12.50$ & $\$ 1.25$ \\
\hline Teletype Model 40 & $\$ 220.00$ & $\$ 22.00$ & $\$ 2.20$ \\
\hline
\end{tabular}

is equal between terminals. Using that graphic analysis, one can see that each speed of terminal has its best use. (See Table 5.)

\section{Summary and Conclusions}

A methodology is presented which should be helpful to the librarian in determining an optimal computer terminal. Included is a systematic analysis of all costs involved and a method of a calculating average cost per search. The authors emphasize that this is merely a demonstration of a technique developed to minimize costs of the on-line com-

$\cos T / \mathrm{MO}$.

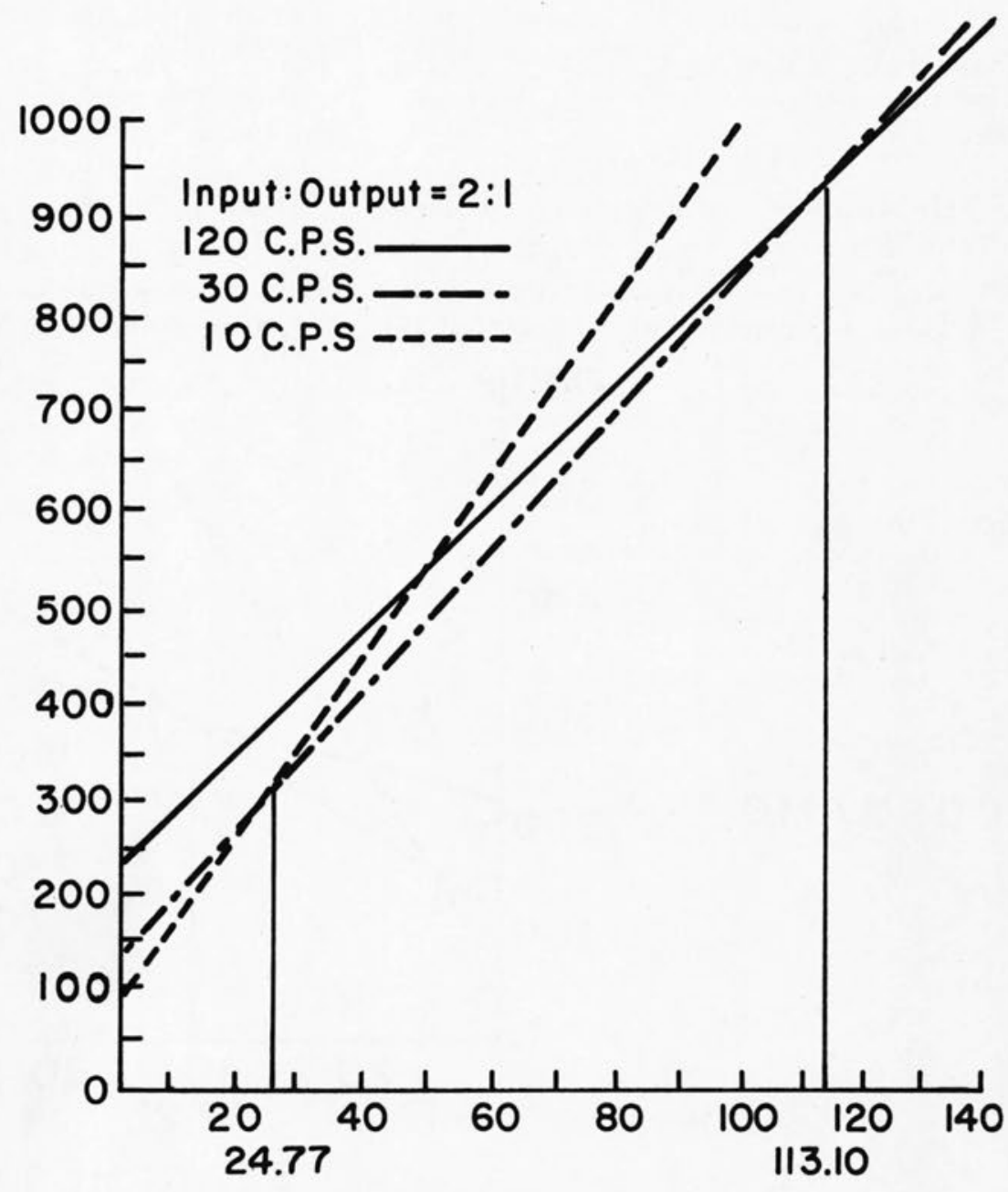

SEARCHES / MO.

Fig. 3

Calculating the minimum cost (input $:$ output $=2: 1$ ). 
puterized information retrieval system. The costs used are indicative.

Terminals are expensive. If the librarian has a terminal he or she is now using for another purpose (i.e., interlibrary loans), it usually can be modified for on-line searching. Such a conversion provides an inexpensive way of getting into computerized searching.

As the demand for searches increases, at some point a faster terminal will likely minimize cost per search given all other costs remaining equal. For example: Table 5 shows that if a literature searcher performs over forty-two searches per month at an input : output ratio of $1: 9$, he or she would economically choose the Model 40 Teletype at 120
CPS. If the input: output ratio was $2: 1$, the literature searcher would choose the CDI 1030 at 30 CPS.

This methodology can serve as a useful planning tool to budget money and provide savings to the library through maximizing the efficiency of the on-line system.

\section{TABLE 5}

Range of Searches Where Each of Three Terminals Provides the Least Total Cost

\begin{tabular}{lccc}
\hline \hline Cheapest Terminal & $\begin{array}{c}\text { Speed } \\
\text { CPS }\end{array}$ & $\begin{array}{c}\text { Input : output } \\
1: 9\end{array}$ & $\begin{array}{c}\text { Input : output } \\
2: 1\end{array}$ \\
\hline $\begin{array}{l}\text { Teletype } \\
\text { Model 33 }\end{array}$ & 10 & $1-9$ & $1-25$ \\
$\begin{array}{l}\text { CDI 1030 } \\
\text { Teletype }\end{array}$ & 30 & $10-42$ & $26-113$ \\
$\quad$ Model 40 & 120 & over 42 & over 113 \\
\hline
\end{tabular}

\section{REFERENCES}

1. John R. Wish and Mary Ann Wish, "Marketing and Pricing of On-Line Services," paper presented at 4th ASIS Mid-Year Meeting, American Society for Information Science General Session 5, p. 1-16, Washington, D.C., May 1975.

2. Stanley A. Elman, "Cost Comparison of Manual and On-Line Computerized Literature Searching," Special Libraries 66:12-18 (Jan. 1975).

3. Randolph E. Hock, "Providing Access to Externally Available Bibliographic Data Bases in an Academic Library," College d Research Libraries 36:214 (May 1975).

4. Jane H. Bonn and Philipp R. Heer, "Terminal Equipment for On-Line Interactive Information Retrieval Using Telecommunications," Special Libraries 67:30-39 (Jan. 1976).

5. "SDC Loses Medical Data Base Customers to National Library of Medicine," Ad- vanced Technology Libraries 4:1 (Feb. 1975).

6. Jeffrey Katzer, "The Cost Performance of an On-Line, Free Text Bibliographic Retrieval System," Information Storage and Retrieval 9:321-29 (June 1973).

7. Wish and Wish, "Marketing and Pricing."

8. Elman, "Cost Comparison."

9. Alan R. Benenfield, and others, "NASIC at MIT Final Report (March 1974)," Report ESL-FR-587, Feb. 28, 1975, Electronic Systems Laboratory, Massachusetts Institute of Technology, Cambridge.

10. The three-volume, loose-leaf Datapro 70, the EDP Buyer's Bible is especially useful to anyone contemplating purchase of computer terminals. See especially "All About Teleprinter Terminals" (March 1976) and "All About Alphanumeric Display Terminals" (April 1976). 